DOI 10.31489/2020No2/31-38

UDC: $621.793-036: 678$

\title{
COMPOSITION AND STRUCTURE OF COMPOSITE COATINGS BASED ON METAL OXIDES AND POLYTETRAFLUOROETHYLENEDEPOSITED UNDER CONDITIONS OF ELECTRON-INITIATED ENDOTHERMIC PROCESSES
}

\author{
Surzhikov A.P. ${ }^{1}$, Chicherina N.V. ${ }^{1}$, Rogachev A.V. ${ }^{2}$, Yarmolenko M.A. ${ }^{2}$, \\ Rudenkov A.S. ${ }^{2}$, Rogachev A.A. ${ }^{3}$, Wang Jicheng ${ }^{4}$ \\ ${ }^{1}$ National Research Tomsk Polytechnic University, Tomsk, Russia, surzhikov@tpu.ru \\ 2FranciskSkorina Gomel State University, Gomel, Belarus, rogachevav@mail.ru \\ ${ }^{3}$ Institute of Chemistry of New Materials of the National Academy of Sciences of Belarus, Minsk, Belarus \\ 4Jiangnan University,Wuxi, China
}

\begin{abstract}
In this article features of physicochemical processes initiated by the low-energy electron flow between the components of the target based on nitrates of metals and metals, their influence on the kinetics of the formation of volatile products, the chemical composition and structure of the deposited coatings are established. When electrons act on a mixture of aluminum nitrate and dispersed aluminum, zinc oxide coatings containing zinc nanorods are formed. The impact of the electron flow on a mechanical mixture of powders of iron nitrate and dispersed aluminum is accompanied by explosive evaporation of the target, and a large number of microdroplet formations deposited at the final stage of exothermic reactions in the surface layers of the target are fixed on the surface of the coating containing oxides and metal nanoparticles. The features of the structure and chemical composition of coatings deposited from the volatile products of electron beam dispersion of a mechanical mixture of polytetrafluoroethylene, iron nitrate, and aluminum are determined. It is shown that under such conditions of generation of the gas phase, coatings are formed consisting of a polymer matrix and containing particles of oxide, a free metal, and a certain amount of the initial undecomposed salt. The result of exothermic reactions in the crucible is partial defluorination and increased defectiveness of the molecular structure of the fluoroplastic matrix.
\end{abstract}

Keywords:spectral analysis, signal, sensor, process, characteristic

\section{Introduction}

Synthesis of nanocomposite coatings based on polymers, metal clusters and their oxides is promising in the production of LEDs, solar cells, piezoelectric transducers [1], gas sensors [2], optical filters. The search for new technological methods of deposition of composite metal-containing coatings is an urgent task of physics and technology of thin-film systems [3, 4]. In recent years, plasmochemical methods of deposition of polymer coatings and surface modification have been actively developed, which are based on processes for creating an active gas phase containing polymerizable molecular fragments [5-8]. The methods are characterized by high efficiency, versatility (there are practically no restrictions on the selection of individual components of the composite coating), a large set of technological techniques for changing the composition, structure and properties of the formed materials, which allows the synthesis of complex thin film systems, the formation of which by other methods is impossible or requires the implementation of a multi-stage technologically complex application process [9-12].

Thus, when using an electron stream to generate a gas phase, polymer-polymer, metal-polymer, polymer-oxide systems are formed, characterized by high mechanical, physical and chemical properties [1315]. At the same time, the flow of electrons during its action on the target material has a complex effect on the ongoing processes. In addition to the thermal effect on the target, which leads to dissociation of complex compounds, their evaporation or dispersion, radiation activation of chemical processes, synthesis of new compounds, which, being on the surface of the target, change the conditions for generating the gas phase, its composition and activity, are possible. The most significant effect of these processes is on targets containing 
complex organic, including high molecular weight or inorganic compounds. It is worth noting that the action of electrons on the polymer target produces a stream of secondary electrons, which also have an initiating effect on dispersion products in the gas phase [16-18].

The main objective of the present work is to establish the influence of exothermic processes that occur under the influence of a low-energy electron flow in a vacuum on mechanical mixtures based on metal nitrate and aluminum, polytetrafluoroethylene (PTFE) on the kinetics of the formation of volatile products, the composition and structure of the resulting layers.

\section{Experiment procedure}

Coatings were precipitated from the gas phase generated by exposing the original target to an electron stream with an energy of 800-1600 eV and a density of $0.01-0.03\left(\mathrm{~A} / \mathrm{cm}^{2}\right)$ [19]. Process of sedimentation of coatings was made with an initial pressure of residual gases in the vacuum unit $\left(\approx 4 \cdot 10^{-3} \mathrm{Pas}\right)$. Powders of nine-water iron (III) nitrate $\left(\mathrm{Fe}\left(\mathrm{NO}_{3}\right)_{3} \cdot 9 \mathrm{H}_{2} \mathrm{O}\right)$, dispersed aluminum, PTFE were used as the target material. The targets were manufactured by thoroughly mixing various powders in an agate mortar. A composite target based on PTFE and a mixture of dispersed aluminum with iron nitrate was made in two steps. In the first step, the inorganic components were mixed. In the second step, PTFE was added to the mortar with the prepared mixture of inorganic powders in small portions and mixed thoroughly with a pestle. The weight ratio of organic to inorganic components was 1:1.

The substrates during the sedimentation of the layers were quartz plates (during spectroscopic measurements in the ultraviolet and visible regions), $\mathrm{NaCl}$ plates (during infrared (IR) spectroscopic (IKspectroscopic studies), silicon single crystal plates(during atomic force microscopy (AFM) and scanning electron microscopy (SEM) studies). The substrate temperature at sedimentation was as follows: $25^{\circ} \mathrm{C}$.

Annealing of the formed coatings was carried out in air at a temperature of $250^{\circ} \mathrm{C}$ for 60 minutes. In some cases, annealing was performed at $500^{\circ} \mathrm{C}$. The IR spectroscopic studies were conducted on Fourier's IR spectrophotometer Vertex-37 (Bruker).UV-View spectroscopic studies were conducted using a Cary-50 spectrophotometer (Varian). The band gap width was determined by the method used in [20] based on the analysis of the optical absorption spectra.The study of morphology, distribution of chemical elements on the surface of thin coatings was carried out using an electron microscope (SEM, Quanta200F) with EDAX microanalysis.

\section{Results and discussion}

At the first stage the features of electronic dispersion of target containing dispersed zinc and zinc nitrate are determined. It has been found that the use of such a target makes it possible to form continuous coatings based on zinc oxide. The interplane distance of the coating applied using the composite target is $0.281 \mathrm{~nm}$, which is in good accordance with $\mathrm{ZnO}$ (1010) [21].

The effect of the electron flux on the target is accompanied by a dazzlingly white glow indicating a high temperature in the electron exposure zone. A zinc oxide sublimation process was identified as the main reason for the formation of the thin coating $\mathrm{ZnO}$. It is worth noting that the sublimation temperature of the $\mathrm{ZnO}$ is $1800^{\circ} \mathrm{C}$ and cannot be achieved in the dispersion zone using a low energy electron flow, as well as due to the decomposition energy of the nitrate (endothermic reaction). In addition to the marked dazzling white glow in the dispersion zone, the high temperature was indicated by the presence of metallic zinc nanoparticles in the precipitated thin layer. As is known, the melting point of zinc exceeds $400^{\circ} \mathrm{C}$. Thus, a high temperature is achieved in the target electron exposure zone due to the exothermic reactions between the target components initiated by the thermal radiation electron beam. The analysis shows that chemical processes with the formation of zinc oxide in two stages are most likely:

$$
1 \mathrm{Zn}\left(\mathrm{NO}_{3}\right)_{2} \cdot 6 \mathrm{H}_{2} \mathrm{O}+5 \mathrm{Zn}=\mathrm{Zn}\left(\mathrm{NO}_{2}\right)_{2}+2 \mathrm{ZnO}+3 \mathrm{Zn}(\text { residue })+6 \mathrm{H}_{2} \mathrm{O} \uparrow+\mathrm{Q} \text {, }
$$

where $\mathrm{Q}$ is moderate heating.

$$
2 \mathrm{Zn}\left(\mathrm{NO}_{2}\right)_{2}+2 \mathrm{ZnO}+3 \mathrm{Zn}=6 \mathrm{ZnO}+\mathrm{N}_{2} \uparrow+\mathrm{Q} \text { where } \mathrm{Q} \text { is intensive heating. }
$$

Further, the features of electron-beam dispersion of copper and iron nitrates were considered. It has been established that the process of water salts is characterized by the presence of two characteristic periods. The first is the melting of salt in crystallization water, followed by the splitting of water molecules from the salt. In the vacuum chamber, the process of separating water molecules is accompanied by a monotonous 
increase in pressure in the vacuum chamber, without any noticeable changes in the readings of the quartz thickness meter. The second is the intensive formation of the gas phase by products of thermal radiation decomposition of metal salts. According to IR spectroscopic analysis, the gas phase in the second period of electron beam dispersion of nitrates forms salt molecules that are intensively evaporated by an electron flow.

Heating of formed copper nitrate coating is accompanied by formation of copper oxide coating. The result is expected because the thermal degradation reaction of anhydrous copper nitrate can be recorded as follows:

$$
2 \mathrm{Cu}\left(\mathrm{NO}_{3}\right)_{2}=2 \mathrm{CuO}+4 \mathrm{NO}_{2} \uparrow+\mathrm{O}_{2} \uparrow
$$

Electron beam dispersion of ninety-water iron (III) nitrate has features. The effect of the electron stream on the salt is accompanied by the melting of the salt in crystallization water and its intensive transition to the gas phase. In contrast to zinc nitrate no intense plasma glow was recorded at a late stage of electron beam impact on powder $\mathrm{Fe}\left(\mathrm{NO}_{3}\right)_{3} \cdot 9 \mathrm{H}_{2} \mathrm{O}$. The IR spectrum of the formed coating coincides with the IR spectrum of the original iron salt powder. Annealing of the formed coatings is accompanied by salt decomposition to form iron oxide. The band gap width $\left(\mathrm{E}_{\mathrm{g}}\right)$ for the $\mathrm{Fe}_{2} \mathrm{O}_{3}$, determined by extrapolation of the dependence $(\mathrm{Dh} v)^{2}$ on the photon energy, is 2.2-2.4 (eV) (Figure 1).

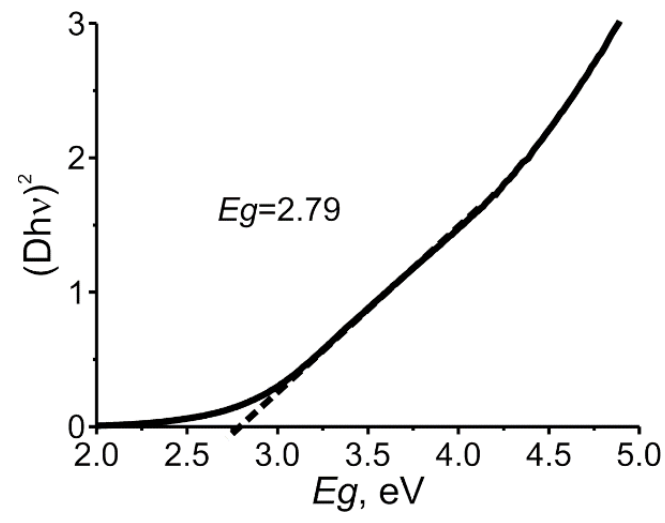

a

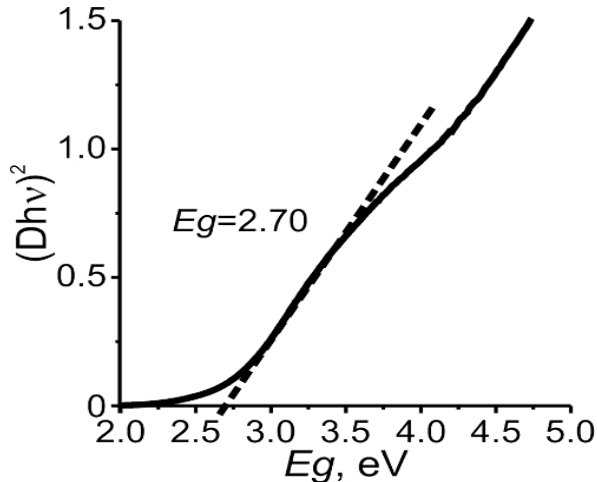

$\mathrm{b}$

Fig.1.Dependence $(\mathrm{Dh} v)^{2}$ on photon energy for $\mathrm{Fe}\left(\mathrm{NO}_{3}\right)_{3} \cdot 9 \mathrm{H}_{2} \mathrm{O}$ coatings annealed at: a) $250^{\circ} \mathrm{C}$; b) $500^{\circ} \mathrm{C}$

For $\mathrm{Fe}_{2} \mathrm{O}_{3}$ nanoparticles the Eg value can significantly exceed the specified interval of values [22, 23]. Thus, work [11] considers the effect of annealing on the size of nanoparticles $\mathrm{Fe}_{2} \mathrm{O}_{3}$ and the value of the band gap. It is noted that the size of $\mathrm{Fe} 2 \mathrm{O} 3$ particles increases with an increase in the annealing temperature, the electron transition energies approach the value known for a bulk material of $2.2 \mathrm{eV}$ : a decrease in the width of the gap zone from 3.51 to $2.76 \mathrm{eV}$ occurs. Thus, on the basis of $\mathrm{Fe}\left(\mathrm{NO}_{3}\right)_{3} \cdot 9 \mathrm{H}_{2} \mathrm{O}$ with increase in temperature of annealing the increase in the size of nanoparticles of oxide of iron can be one of the reasons of reduction of $\mathrm{E}_{\mathrm{g}}$ of coatings.

As in the case of zinc nitrate, to eliminate or reduce the effect of salt melting, it is proposed to use a mechanical mixture of iron nitrate powders and aluminum powder. It is noted that the preliminary thorough mixing of salt and aluminum powder can significantly level the process of salt melting. This is due to chemical interactions between the components in the mixing step. Indirectly, this is indicated by the fact that when mixed, the powder becomes brown due to the formation of iron oxide. The thermal radiation effect of the electron stream should be accompanied by decomposition of nitrate to oxide to form a finely dispersed mixture of iron oxide and aluminum. At the same time, the heat generated as a result of the reaction will be responsible for the intensive formation of a gas-phase stream of dispersion products.

However, preliminary studies of electron beam dispersion of the mixture of salt and aluminum showed the absence of exothermic reactions. The main reasons are the low energy of the electron flow and insufficient mechanical contact between the target components. The absence of contact under vacuum conditions prevents the chemical interaction between salt and aluminum powder. It should be noted that in aluminum powder, aluminum is protected from interaction with the environment by fat additives. Thus, in order to conduct chemical interactions between salt and aluminum, it is necessary to achieve good mechanical contact and destroy the protective film. The destruction of the fat film is easily effected by a low energy electron flux. Good mechanical contact was achieved by thoroughly mixing the target components in diethyl ether. The short effect of the electron flow in a vacuum on the mechanical mixture prepared in this 
way initiates a violent chemical reaction resulting in explosive evaporation of the target material.Peculiarities of morphology of deposited coatings and their chemical composition are established. Figure 2 shows the IR spectra of coatings based on iron nitrate and aluminum powder formed as a result of the implementation of such an interaction.

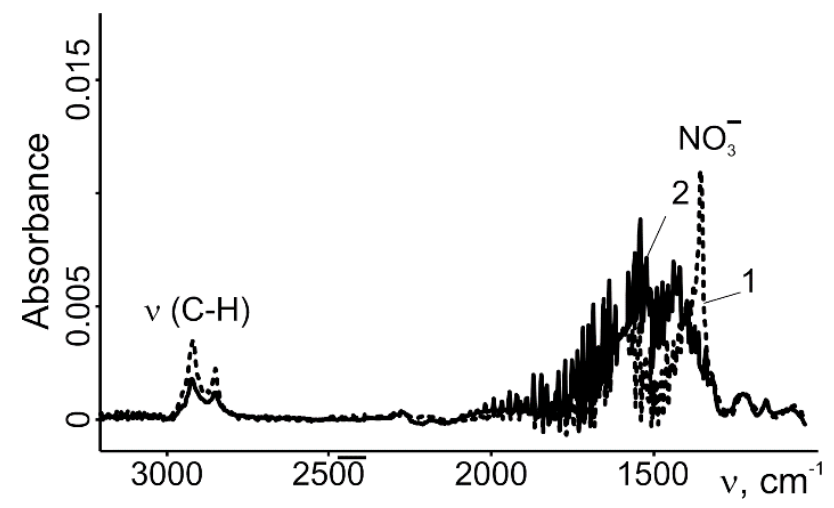

Fig.2. IR spectra of the coating based on $\mathrm{Fe}\left(\mathrm{NO}_{3}\right)_{3} \cdot 9 \mathrm{H}_{2} \mathrm{O}$ and aluminum powders:

1 -without heat treatment; 2 - heat treatment $250^{\circ} \mathrm{C}$, 1 hour.

Faintly noticeable absorption bands are recorded in the spectrum due to the presence of $\mathrm{C}-\mathrm{H}$ and $\mathrm{NO}_{3}$ groups in the thin layer [13]. Thus, the high reaction temperature and explosive nature of the reaction initiate rapid decomposition of the salt. There is practically no undissolved salt in the formed reaction product stream. Thermal treatment of the coating is accompanied by complete decomposition of iron nitrate (Fig.2). Figure 3 shows the results of SEM studies of coatings formed under conditions of exothermic interaction between iron nitrate and aluminum. On surface of the formed layer there is a large number of microdrops, indicating the explosive nature of the application (Fig.3,a). The coating itself is solid and defect-free (Fig.3, b). Droplet formation occurs at the final stage of exothermic interaction in the target. Chemical analysis of various microdroplets shows a high content of aluminum in them, while the lower defect-free layer (analysis was carried out at various points) is characterized by a high content of iron (Table 1).

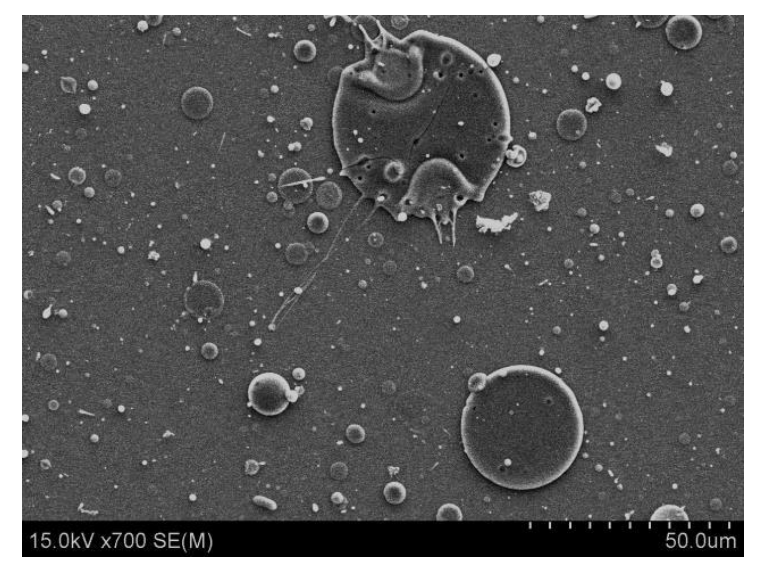

a

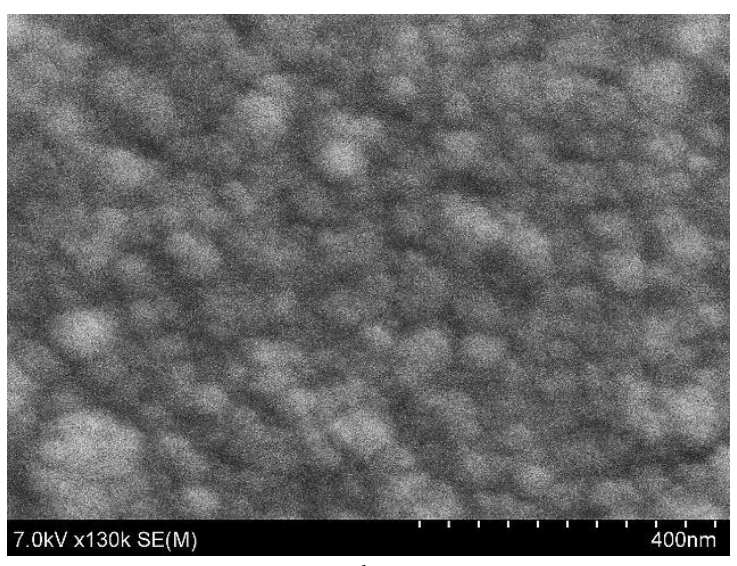

b

Fig.3.Results of SEM studies of coatings based on $\mathrm{Fe}\left(\mathrm{NO}_{3}\right)_{3} \cdot 9 \mathrm{H}_{2} \mathrm{O}$ and aluminum powder

Table 1 - Chemical composition of thin layer

\begin{tabular}{|l|c|c|c|}
\hline \multirow{2}{*}{\multicolumn{1}{|c|}{ Objecttobeanalyzed }} & $\mathrm{Fe}$ & $\mathrm{Al}$ & $\mathrm{O}$ \\
\cline { 2 - 4 } & \multicolumn{3}{|c|}{ at. \% } \\
\hline \hline Microdrop1 & 22.05 & 30.57 & 47.38 \\
\hline Microdrop2 & 11.62 & 35.78 & 52.60 \\
\hline Microdrop3 & 1.36 & 41.01 & 57.63 \\
\hline Bottomsolidlayer & 50.21 & 21.96 & 27.83 \\
\hline
\end{tabular}


Analysis of the chemical composition of the thin layer indicates incomplete metal oxidation; metal nanoparticles are present in the coating along with iron and aluminum oxides.

\section{Formation of coatings based on iron oxide, aluminium and PTFE}

It has been found that exposure of mechanical mixtures containing polymers such as polyethylene, polyurethane to electron flow in vacuum causes melting of the target polymer component, and the resulting melt prevents direct contact of the salt and aluminum particles and, accordingly, chemical interaction. During electron beam dispersion of PTFE, the formation of a viscous-flowing state of the polymer is not observed and contact of iron and aluminum nitrate particles is maintained. The kinetic features of the electron beam dispersion process of organo-inorganic targets are shown in Figure 4.

The effect of electron flow on the composite target is accompanied by an increase in pressure in the vacuum chamber. At the same time, there is a long induction period during which the quartz thickness meter does not record the deposition of the coating. The increase in pressure during the induction period is due to the formation of the gas phase by low molecular weight non-condensing compounds at room temperature. These compounds are the products of salt decomposition: water molecules, nitric acid. Subsequently, there is a local exothermic interaction of inorganic compounds. On the kinetic curve of pressure change, characteristic peaks appear, indicated in Figure 4, b. Bright flashes are visually fixed on the target surface, accompanied by local blackening of the target.

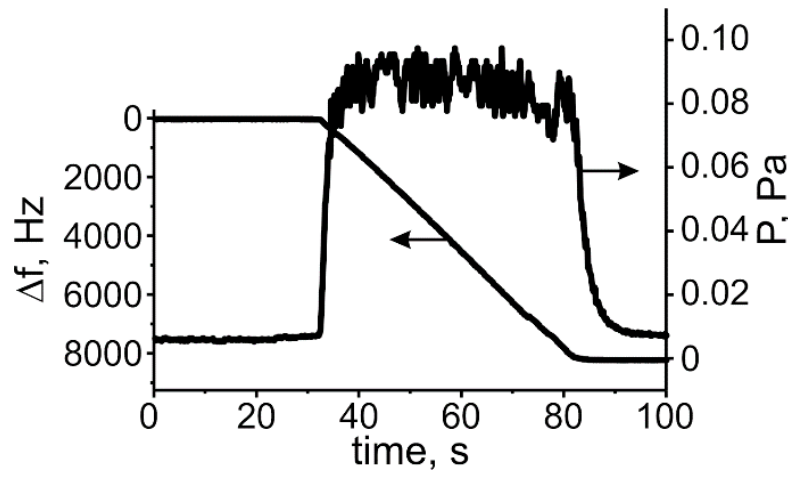

a

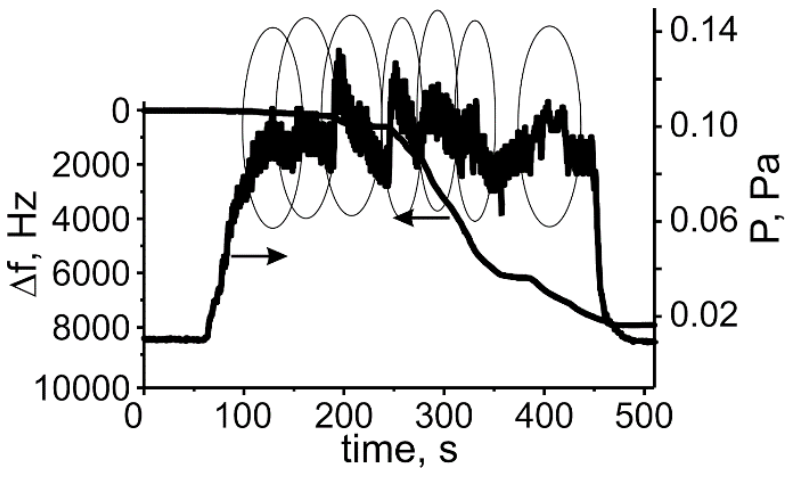

б

Fig.4. Kinetics of electron beam dispersion of PTFE (a) and mixture $\mathrm{Fe}\left(\mathrm{NO}_{3}\right)_{3} \cdot 9 \mathrm{H}_{2} \mathrm{O}+\mathrm{Al}+\mathrm{PTFE}$ (b)

A noticeable amount of the starting salt is present in the formed thin composite layer. In the IR spectrum of the coating, in addition to the absorption bands characteristic of PTFE, the absorption of $\mathrm{NO}_{3}$ and $\mathrm{OH}$ groups is recorded (Figure 5).

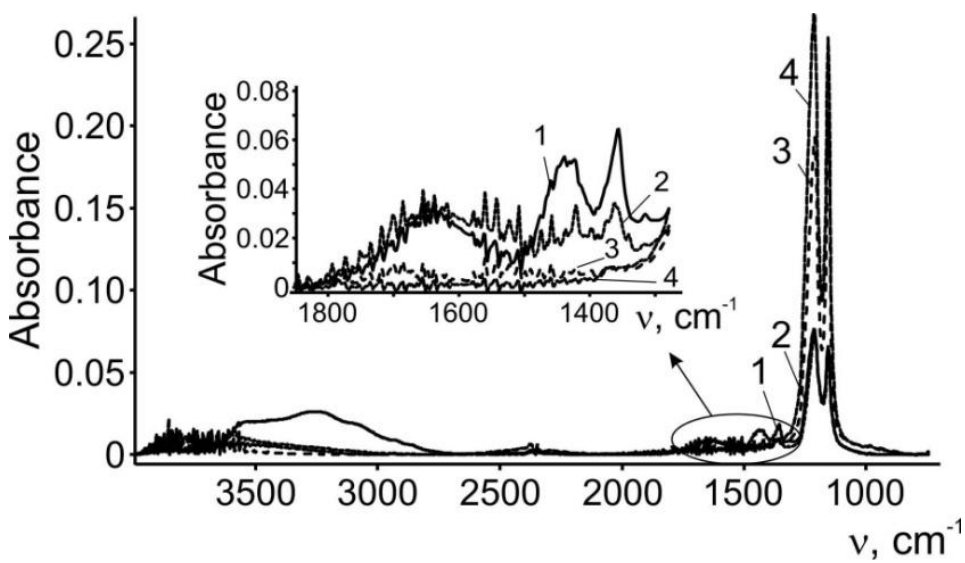

Fig.5. IR spectra of $\mathrm{Fe}\left(\mathrm{NO}_{3}\right)_{3} \cdot 9 \mathrm{H}_{2} \mathrm{O}+\mathrm{Al}+\mathrm{PTFE}$ coatings: without heat treatment (1), $\mathrm{Fe}\left(\mathrm{NO}_{3}\right)_{3} \cdot 9 \mathrm{H}_{2} \mathrm{O}+\mathrm{Al}+\mathrm{PTFE}$ coatings after heat treatment (2), PTFE coatings without heat treatment (3), PTFE coatings after heat treatment (4) 
Valence vibrations of $\mathrm{OH}$ groups are manifested in the range of $3600-2800 \mathrm{~cm}^{-1}$, deformation - near 1640 $\mathrm{cm}^{-1}$ [13]. The presence of water molecules in the thin layer is due to the non-deposited salt intensively sorbing atmospheric moisture. Annealing is accompanied by salt decomposition and desorption of adsorbed moisture. The effect of inorganic components and the generated heat flux on the molecular structure of PTFE was judged by absorption bands at 638 and $625 \mathrm{~cm}^{-1}$. The strip at $625 \mathrm{~cm}^{-1}$ is referred to a defective structure, and the strip at $638 \mathrm{~cm}^{-1}$ is associated with the presence of a regular spiral [13]. The analysis was carried out after heat treatment of the formed coatings. For the composite coating, the ratio of $\mathrm{D}_{638} / \mathrm{D}_{625}$ corresponds to 1.40 and for the PTFE thin layer to 1.84. The consequence of exothermic reactions is a predicted increase in the defect of the molecular structure of the fluoroplastic matrix.

The morphology of the composite layer in comparison with the morphology of PTFE is more "loose" and porous, there is a significant number of small drop-like formations that form larger surface structures (Figure 6). It can be assumed that the deposition of the composite layer, unlike the PTFE single-component coating, occurs under conditions of insufficiently high density of active fragments of PTFE macromolecules and their increased adsorption activity. It should be noted that thermal effect in vacuum on PTFE is accompanied by generation of a chemically inactive monomer. Activation of the monomer requires additional physical influence: treatment with an electron flow, discharge plasma, etc. The results of atomic force microscopy (AFM) studies indicate a significant effect of thermal effects on the morphology of the deposited layer.
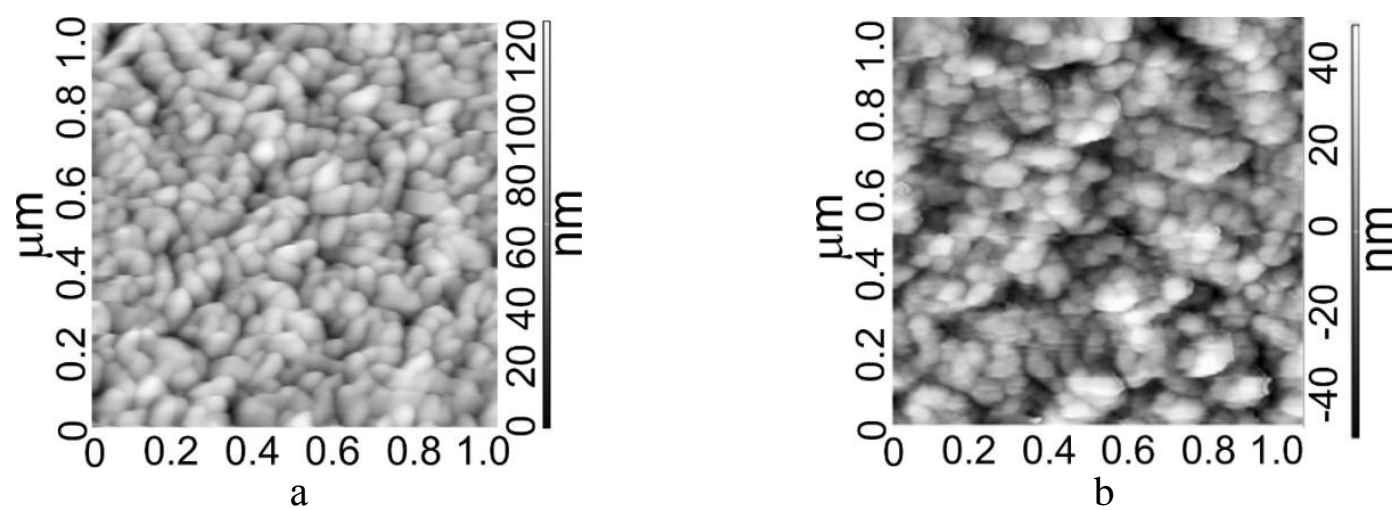

Fig.6. AFM images of coatings obtained by dispersing PTFE (a) and $\mathrm{Fe}\left(\mathrm{NO}_{3}\right)_{3} \cdot 9 \mathrm{H}_{2} \mathrm{O}+\mathrm{Al}+\mathrm{PTFE}$ (b)

It should be noted that the deposited coating composition is non-uniform in thickness. That is why during its annealing with the help of SEM, a discontinuity was established, the presence of local areas, the formation of which can be explained by the decomposition of iron nitrate, the vapors of which are present in volatile dispersion products (Figure 7).
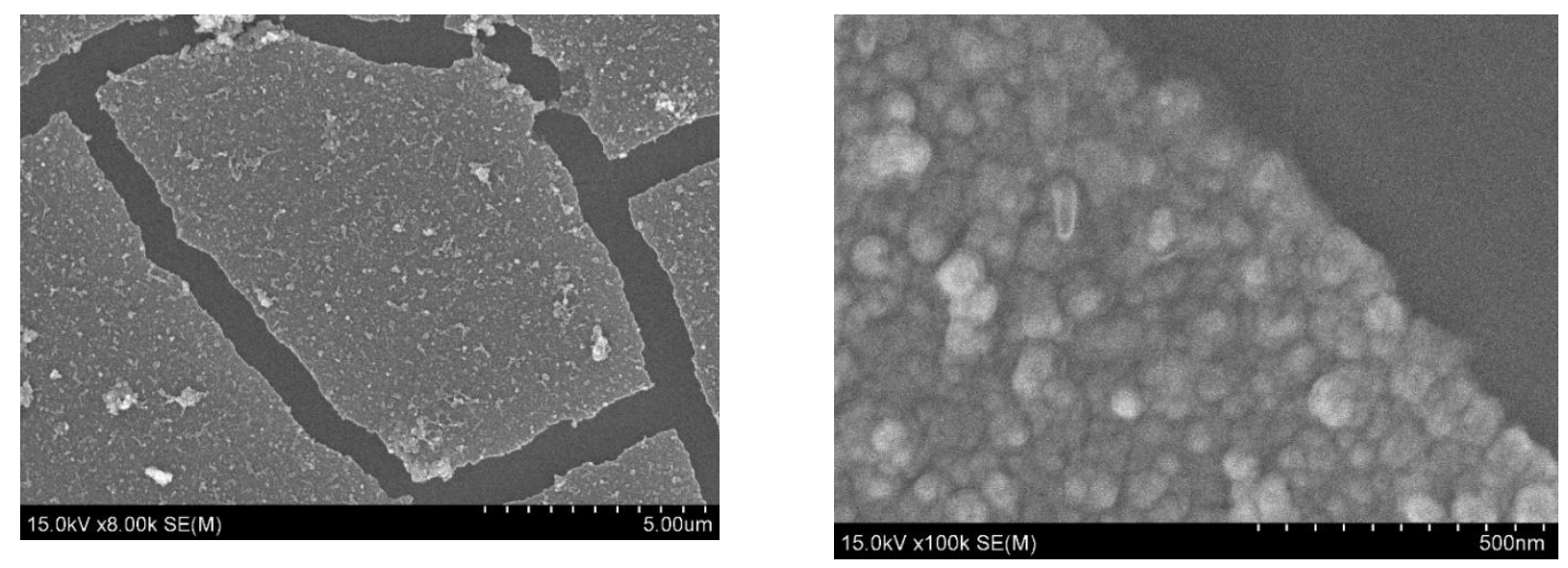

Fig.7.SEM image of coating based on $\mathrm{Fe}\left(\mathrm{NO}_{3}\right)_{3} \cdot 9 \mathrm{H}_{2} \mathrm{O}+\mathrm{Al}+\mathrm{PTFE}$ subjected to heat treatment with different zoom 
High heterogeneity of deposited coatings is confirmed by the results of their chemical analysis (Table 2). Large droplets (Fig. 8) on the surface of the coating are the result of melting and evaporation of aluminum powder. Dispersion of the composite target is accompanied by defluorination processes of the organic component. If in the starting polymer the ratio of carbon atoms to fluorine is $1: 2$, so in the coating it is approximately the same or the number of fluorine atoms is less, which is possible when cluster carbon structures are formed in the coating volume, or when forming macromolecules of the form $[-\mathrm{C}=\mathrm{CF}-]_{\mathrm{n}}$.

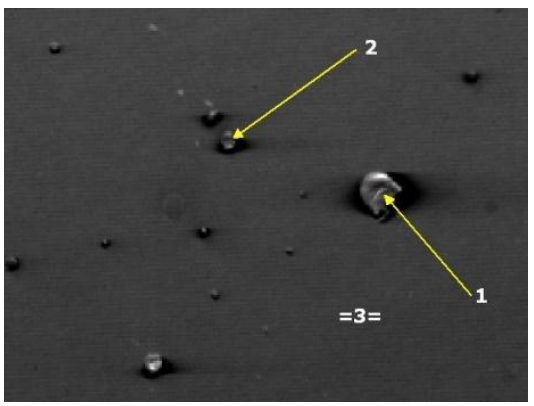

Fig. 8.SEM image of coating based on $\mathrm{Fe}\left(\mathrm{NO}_{3}\right)_{3} \cdot 9 \mathrm{H}_{2} \mathrm{O}+\mathrm{Al}+\mathrm{PTFE}$

Table 2 - Chemical composition of composite coating areas

\begin{tabular}{|l|c|c|c|c|c|}
\hline \multirow{2}{*}{ Object to be analyzed } & $\mathrm{Fe}$ & $\mathrm{Al}$ & $\mathrm{O}$ & $\mathrm{C}$ & $\mathrm{F}$ \\
\cline { 2 - 6 } & \multicolumn{5}{|c|}{ at. \% } \\
\hline \hline 1 & 3.31 & 13.90 & 4.31 & 35.50 & 42.98 \\
\hline 2 & 14.46 & 12.52 & 14.22 & 30.23 & 28.56 \\
\hline 3 & 4.14 & 8.51 & 11.15 & 45.26 & 30.94 \\
\hline
\end{tabular}

According to the chemical analysis, a certain fraction of the metal in the thin layer is not present in the oxidized state. The results are consistent with UV-Type spectroscopy data: the value of the band gap cannot be determined based on electronic spectra. This indicates a low concentration of oxide in the organic layer.

\section{Conclusion}

Peculiarities of electron-beam dispersion of mechanical mixtures based on aluminium, copper, iron and dispersed aluminium nitrate are considered. Under the influence of low-energy electrons on a mixture of aluminum nitrate and dispersed aluminum, the formation of zinc oxide coatings containing zinc nanosupples was established, which indicates a significant effect of exothermic reactions between the target components on the formation of volatile products and their chemical composition of the deposited coatings. It is noted that the effect of electron flow on the mechanical mixture of iron nitrate powders and dispersed aluminum is accompanied by explosive evaporation of the target. A large number of microdroplet formations deposited at the final stage of exothermic interaction in the target are fixed on the surface of the thin layer. Chemical analysis of the lower defect-free layer showed a high iron content (more than 50 at\%), the formation of a coating containing metal oxides and nanoparticles.

The principle possibility of sedimentation of polymer coatings containing oxides, metal nanoclusters is established by electron-beam dispersion of mechanical mixtures under conditions of exothermic processes in the target. It has been shown that by dispersing the mechanical mixture of PTFE, iron nitrate, iron nitrate and aluminum nitrate, coatings are formed consisting of a polymer matrix and containing particles of oxide, free metal and a certain amount of the original non-deposited salt. The consequence of exothermic reactions in the crucible is partial deflection and increased defects in the molecular structure of the fluoroplastic matrix.

\section{Acknowledgements}

The work was carried out with the financial support of the Ministry of Education of the Republic of Belarusas a task 2.4.04 "Development of physical and chemical foundations of methods for activation of gas phase generation processes using exothermic and endothermic reacting chemicals" and the research is carried out at Tomsk Polytechnic University within the framework of Tomsk Polytechnic University Competitiveness Enhancement Program grant. 


\section{REFERENCES}

1 Bryanskikh T.V., Kokourov D.V. Energy efficiency of electric furnaces with movable floor in firing of vermiculite concentrates of different size groups. Refractories and Industrial Ceramics, 2017, Vol. 58, pp. 368-373.

2 Zhuravlev V.A., Naiden E.P., Minin R.V., Itin V.I., Suslyaev V.I., Korovin E.Yu. Radiation-thermal synthesis of W-type hexaferrites. IOP onference Series: Materials Science and Engineering. 2015, Vol. 81, Article number 012003. https://doi.org/10.1088/1757-899X/81/1/012003.

3 Santamaria A., Faleschini F., Giacomello G., Brunelli K., Pasetto M. Dimensional stability of electric arc furnace slag in civil engineering applications. Journal. of Cleaner Production. 2018, Vol. 205, pp. 599-609.

4 Sharipov M.Z., Mirzhonova N.N., Hayitov D.E. Effect of inhomogeneous radially directed mechanical stresses on the domain structure of a FeBO3 single crystal. Eurasian phys. tech. j. 2019, Vol.16, No.1, pp. 35 - 41.

5 Surzhikov A.P., Malyshev A.V., Lysenko E.N., Vlasov V.A., Sokolovskiy A.N. Structural, electromagnetic, and dielectric properties of lithium-zinc ferrite ceramics sintered by pulsed electron beam heating. Ceramics International. 2017, Vol. 43, No. 13, pp. 9778-9782. DOI: 10.1016/j.ceramint.2017.04.155

6 Yarmolenko M.A. Plasma-chemical modification of sealing rubber products based on nitrile butadiene rubber: structure and antifriction properties of surface layers, Extended abstract of D.Ph. thesis, Gomel, Institute of Mechanics of Metal-Polymer Systems named after V. A. Bely of the National Academy of Sciences of Belarus. 2006,24 p.

7 Patil U.V., Rout C.S., Late D.J. Impedimetric humidity sensor based on $\alpha-\mathrm{Fe}_{2} \mathrm{O}_{3}$ nanoparticles. Advanced Device Materials. 2015, Vol. 3, pp. 88-92.

8 Shkarin A.V., Zhabrova G.M., Topor N.D., KushnarevM.Ya. Thermal stability and chemical transformations of oxalates. Bulletin of the Tomsk Institute named after C.M.Kirov 1969, Vol. 199, pp. $105-111$.

9 Kolesnikov V.N. Forms of carbon formed during thermolysis of formates of metals of the iron subgroup. Bulletin of the Kharkov National University. 2011, Vol. 976, No 20, pp. $247-253$.

10 Myagkov V.G., Zhigalov V.S., Bykova L.E., Maltsev V.K. Self-propagating high-temperature synthesis and solid-phase reactions in two-layer thin films. Technical Physics Journal. 1998, Vol. 68, pp. 58 - 62.

11 Myagkov V.G., Bykova L.E., Bondarenko G.N. Self-propagating high-temperature synthesis and formation of quasicrystals in two-layer Al / Mn thin films. Journal of Experimental and Theoretical Physics Letters. 1998, Vol. 68, pp. $121-124$.

12 Yarmolenko M.A., Rogachev A.A., Luchnikov P.A., Rogachev A.V., Hong Jang Xian. Micro- and nanocomposite polymer coatings deposited from the active gas phase. Radiotekhnika, Moscow, 2016, 424 p.

13 Surzhikov A.P., Peshev V.V., Pritulov A.M., Gyngazov S.A. Grain-boundary diffusion of oxygen in polycrystalline ferrites. Russian Physics Journal. 1999, Vol. 42, No. 5, pp. 490-495. DOI: 10.1007/BF02508222

14 Investigation of structural properties of electron-beam deposition of zinc oxide coatings doped with copper Surfaces and Interfaces. 2017. Vol. 6, pp. $24-32$.

15 Kharlamova M.V., Sapoletova N.A., Eliseev A.A, Lukashin A.V. Optical properties of $\gamma$-iron oxide nanoparticles in a mesoporous silicon oxide matrix. Journal of Experimental and Theoretical Physics Letters. 2008, Vol. 34, No 7, pp. $36-43$.

16 Gutnik V.A., Khalipova O.S., Kuznetsova S.A. Gutnik, V.A. The effect of salicylic acid on the properties of $\mathrm{Fe}_{2} \mathrm{O}_{3}$ films obtained from a film-forming solution based on iron (III) chloride. Bulletin of Tomsk State University. Chemistry. 2015, No 2, pp. 76-86.

17 Rogachev A.V., Yarmolenko M.A., Rogachev A.A., Gorbachev D.L., Zhou B. Chemical composition, morphology and optical properties of zinc sulfide coatings deposited by low-energy electron beam evaporation. Applied Surface Science. 2014, Vol. 303, pp. 23-29.

18 Barman B., Sarma K.C. Luminescence properties of $\mathrm{ZnS}$ quantum dots embedded in polymer matrix. Chalcogenide Letters. 2011, Vol. 8, No 3, pp. 171 - 176.

19 Karipbayev Zh., Alpyssova G., Mussakhanov D., et al. Time-resolved luminescence excited with $\mathrm{N}_{2}$ laser of YAG:CE Ceramics formed by electron beam assisted synthesis. Eurasian Physical Technical Journal. 2020, Vol.17, pp. 73-76. https://doi.org/10.31489/2020NO1/73-76.

20 Dekhant I. Infrared spectroscopy of polymers. Khimiya, Moscow, 1972, 472 p. [in Russian]

21 Surzhikov A.P., Frangulyan T.S., Ghyngazov S.A., Lisenko E.N., Galtseva O.V. Physics of magnetic phenomena: Investigation of electroconductivity of lithium pentaferrite. Russian Physics Journal. 2006, Vol. 49, No. 5, pp. 506 - 510. DOI: 10.1007/s11182-006-0133-6

22 Ridgley D.H., Lessoff H., Childress J.V. Effects of Lithium and Oxygen Losses on Magnetic and Crystallographic Properties of Spinel Lithium Ferrite. Journal of the American Ceramic Society. 1971, Vol.53, pp. 304 - 311. https://doi.org/10.1111/j.1151-2916.1970.tb12113.x.

23 Mazen S.A., Abu-Elsaad N.I. Structural, magnetic and electrical properties of the lithium ferrite obtained by ball milling and heat treatment. Applied Nanoscience. 2015, Vol. 5, pp. 105 - 114. https://doi.org/10.1007/s13204-0140297-2. 